\title{
STATUS HARA TANAH DAN PERTUMBUHAN PEPAYA CALIFORNIA (Carica papaya L.) TERHADAP MOL NASI BASI
}

\section{SOIL NUTRITION STATUS AND GROWTH OF CALIFORNIA PAPAYA (Carica papaya L.) TO SPOILED RICE MOL}

\author{
Siti Mutmainah ${ }^{1}$, Ahmad Sufillah Zaelani ${ }^{2}$ \\ ${ }^{1}$ Tenaga Pendidik Prodi Agroteknologi Faperta Universitas Widya Gama Mahakam \\ ${ }^{2}$ Mahasiswa Prodi Agroteknologi Faperta Universitas Widya Gama Mahakam \\ sitimutmainah@uwgm.ac.id
}

\begin{abstract}
Papaya is a tropical fruit that is easy to cultivate and is one of the fruits that is widely consumed by people in Indonesia. Papaya California is one of the papaya varieties that are favored by the public because it has a sweeter taste than other papaya varieties. In an effort to reduce the use of inorganic fertilizers, the researchers made MOL made from spoiled rice in the hope that it can be used as an alternative in the cultivation of Californian papaya. This study used a randomized block design, where the researchers wanted to see how the MOL response of stale rice to soil nutrient status and growth of California papaya plants. The MOL of spoiled rice consisted of 4 levels, namely: NO = $0 \mathrm{ml} / \mathrm{L}$ (control), N1 = 50 ml/L, N2 $=100 \mathrm{ml} / \mathrm{L}$ and N3 = $150 \mathrm{ml} / \mathrm{L}$. The data obtained were analyzed and further tested with the $5 \%$ BNT test. The results showed that giving MOL of stale rice with this concentration had no significant effect on all observation parameters and was not significant in improving soil nutrient status.
\end{abstract}

Keywords: spoiled rice; Carica papaya L.; soil nutrient

\section{PENDAHULUAN}

Pepaya merupakan salah tanaman holtikultura yang saat ini banyak dibudidayakan oleh para petani, salah satu jenis pepaya yang dibudidayakan adalah pepaya kalifornia atau biasanya disebut pepaya calina. Pepaya Kalifornia adalah varietas pepaya yang rasanya lebih manis, dan dapat dipanen lebih cepat dibandingkan dengan pepaya varietas lain. Selain itu, budidaya pepaya juga mudah dilakukan, karena di daerah tropis tanaman ini memiliki adaptasi yang luas dan tidak bermusim. Produksi pepaya di kota Samarinda pada tahun 2017 hingga 2018 sebesar 11.269 kuintal, dan 27.381 kuintal mengalami peningkatan 143\%/tahun (Badan Pusat Statistik Kota Samarinda, 2019). Data tersebut cukup fluktuatif dan masih berpotensi untuk ditingkatkan

Permasalahan dalam pertanian Indonesia yang sering dijumpai adalah penggunaan pupuk anorganik secara berlebihan dan tidak mempertimbangkan dampak negatifnya bagi manusia, hewan dan lingkungan, yang dapat menyebabkan difisiensi unsur hara tanah. Kebutuhan unsur hara dapat dipenuhi bukan hanya dengan menggunakan pupuk kimia, beragam jenis pupuk organik telah dikembangkan yang bertujuan untuk meminimalisir penggunaan bahan kimia dalam pertanian. Selain berfungsi sebagai membantu proses pertumbuhan dan perkembangan tanaman, pupuk organik juga dapat memperbaiki sifat fisik dan kimia tanah yang rusak akibat penggunaan pupuk kimia yang berlebihan (Arsela, 2018).

Dalam kehidupan sehari hari salah satu makanan pokok yang sering bersisa adalah nasi.
Nasi sisa atau nasi basi ini biasanya dimanfaatkan untuk pakan ternak, bahkan terkadang hanya dibuang begitu saja di tempat sampah tanpa ada pengolahan lebih lanjut hingga menghasilkan bau yang kurang sedap dan pemandangan tidak menyenangkan. Menurut (Selviana, 2019) nasi basi dapat dimanfaatkan untuk membuat mol sebagai pengganti pupuk kimia dalam memenuhi kebutuhan nutrisi bagi tanaman. Mikroorganisme lokal (MOL) adalah larutan hasil fermentasi yang berbahan dasar dari berbagai sumber daya yang tersedia setempat (Sultoni dkk, 2019). MOL bisa diaplikasikan sebagai pupuk organik cair ataupun pupuk hayati yang bisa diaplikasikan langsung pada media tanam. (Julita dkk, 2013). Kandungan unsur hara dalam MOL mempunyai kelengkapan unsur hara yang lengkap. Meskipun unsur haranya dalam jumlah sedikit, tetapi seluruh kebutuhan unsur hara mikro dan makro bagi tanaman dapat terpenuhi. Unsur tersebut diantaranya $\mathrm{N}, \mathrm{P}, \mathrm{K}, \mathrm{Ca}, \mathrm{Mg}, \mathrm{S}, \mathrm{Mn}$, $\mathrm{Fe}, \mathrm{Cu}, \mathrm{Zn}, \mathrm{Mo}$, dan Bo (Sumarno dkk, 2016). Selain itu, dalam mol nasi basi juga mengandung mikroorganisme seperti Rhizopus oligosporus dan Saccharomyces cereviceae.

\section{BAHAN DAN METODE}

Penelitian ini dilaksanakan selama 4 bulan, dimulai pada bulan Februari 2021 sampai dengan bulan Juni 2021 di Kelurahan Rawa Makmur, Kecamatan palaran Kota Samarinda. Alat yang digunakan adalah cangkul, parang, gembor, ember, batang kayu, camera, cuter, meteran, jangka sorong, alat tulis, timbangan, dan kalkulator. Bahan yang 
digunakan dalam penelitian ini adalah benih pepaya kalifornia, nasi sisa, EM4, kotoran kambing, air, gula.

Rancangan yang digunakan adalah Rancangan Acak Kelompok (RAK) satu faktor dengan tiga kali ulangan yaitu respon pupuk organik cair air cucian beras dengan kulit bawang merah yang terdiri dari tiga taraf yaitu:

$\mathrm{N} 0=0 \mathrm{ml} / \mathrm{L}$ (kontrol)

$\mathrm{N} 1=50 \mathrm{ml} / \mathrm{L}$

$\mathrm{N} 2=100 \mathrm{ml} / \mathrm{L}$

$\mathrm{N} 3=150 \mathrm{ml} / \mathrm{L}$

Secara keseluruhan terdapat empat kombinasi perlakuan dan diulang sebanyak tiga kali, sehingga total seluruh tanaman ada dua belas dengan empat tanaman sulam setiap perlakuan.

Variabel pengamatan yaitu : tinggi tanaman $(\mathrm{cm})$ berumur 15, 30, 45, 60, 75 dan 90 hari setelah tanam, umur tanaman pada saat panen pertama, jumlah cabang pertanaman (cabang), jumlah buah pertanaman, dan berat buah pertanaman (gram).

Analisis data, dilakukan uji Anova atau sidik ragam pada tarap 5\% untuk melihat perbandingan respon pertumbuhan tanaman dengan POC yang berbeda dan apabila terdapat pengaruh maka perlu dilakukan uji BNT untuk melihat perbedaannya.

\section{HASIL DAN PEMBAHASAN}

Nasi basi dapat diolah menjadi pupuk maupun mikroorganisme lokal melalui proses fermentasi. Suprihatin (2010) mengungkapkan bahwa fermentasi adalah suatu proses terjadinya perubahan kimia pada suatu substrat organik melalui aktivitas enzim yang dihasilkan oleh mikroorganisme. Nasi basi merupakan salah satu sumber karbohidrat dalam pembuatan larutan Mol.

Mol adalah mikroorganisme lokal, yaitu sekumpulan mikroorganisme yang berfungsi sebagai pupuk organik cair atau starter dalam pembuatan pupuk organik dengan kata lain MOL akan mempercepat proses pengomposan dan sebagai dekomposer yang akan mempercepat penguraian senyawa-senyawa organik. Waktu pembuatan MOL relatif singkat dan cara pembuatannya pun mudah, selain itu mol juga ramah lingkungan (Afcarina, 2018). Larutan MOL mengandung unsur hara mikro dan makro dan juga mengandung bakteri yang berpotensi sebagai perombak bahan organik, perangsang pertumbuhan, dan sebagai agens pengendali hama dan penyakit tanaman, sehingga MOL dapat digunakan baik sebagai dekomposer, pupuk hayati dan sebagai pestisida organik terutama sebagai fungisida (Herniwati \& Nappu, 2018).

Berdasarkan hasil data analisa tanah di laboratorium, diketahui bahwa kandungan tanah yang ditambahan dengan Mol nasi basi sebagai berikut :
Tabel 1. Analisa Tanah N0 (kontrol)

\begin{tabular}{|c|c|c|c|}
\hline NO & PARAMETER & SATUAN & $\begin{array}{c}\text { HASIL } \\
\text { ANALISA }\end{array}$ \\
\hline 1 & $\mathrm{pH}$ & - & 5.29 \\
\hline 2 & N Total & $\%$ & 0.04 \\
\hline 3 & C Organik & $\%$ & 0.56 \\
\hline 4 & $\mathrm{P}_{2} \mathrm{O}_{5}$ & $\mathrm{mgP}_{2} \mathrm{O}_{5} 100 \mathrm{~g}^{-1}$ & 27.96 \\
\hline 5 & $\mathrm{~K}_{2} \mathrm{O}$ & $\mathrm{Cmol}^{-1} \mathrm{~kg}^{-1}$ & 0.40 \\
\hline 6 & $\mathrm{CaO}$ & $\mathrm{Cmol}^{-1} \mathrm{~kg}^{-1}$ & 2.73 \\
\hline 7 & $\mathrm{MgO}$ & $\mathrm{Cmol}^{-1} \mathrm{~kg}^{-1}$ & 2.80 \\
\hline 8 & KTK & $\mathrm{Cmol}^{-1} \mathrm{~kg}^{-1}$ & 9.43 \\
\hline 9 & $\mathrm{C} / \mathrm{N}$ & - & 14.74 \\
\hline
\end{tabular}

Tabel 2. Analisa Tanah N1 (5\% Mol Nasi Basi)

\begin{tabular}{|c|c|c|c|}
\hline NO & PARAMETER & SATUAN & $\begin{array}{c}\text { HASIL } \\
\text { ANALISA }\end{array}$ \\
\hline 1 & $\mathrm{pH}$ & - & 5.21 \\
\hline 2 & N Total & $\%$ & 0.04 \\
\hline 3 & C Organik & $\%$ & 0.37 \\
\hline 4 & $\mathrm{P}_{2} \mathrm{O}_{5}$ & $\mathrm{mgP}_{2} \mathrm{O}_{5} 100 \mathrm{~g}^{-1}$ & 25.56 \\
\hline 5 & $\mathrm{~K}_{2} \mathrm{O}$ & $\mathrm{Cmol}^{-1} \mathrm{~kg}^{-1}$ & 1.77 \\
\hline 6 & $\mathrm{CaO}$ & $\mathrm{Cmol}^{-1} \mathrm{~kg}^{-1}$ & 2.09 \\
\hline 7 & $\mathrm{MgO}$ & $\mathrm{Cmol}^{-1} \mathrm{~kg}^{-1}$ & 2.43 \\
\hline 8 & KTK & $\mathrm{Cmol}^{-1} \mathrm{~kg}^{-1}$ & 8.46 \\
\hline 9 & $\mathrm{C} / \mathrm{N}$ & - & 10.39 \\
\hline
\end{tabular}

Tabel 3. Analisa Tanah N2 (10\% Mol Nasi Basi)

\begin{tabular}{|c|c|c|c|}
\hline NO & PARAMETER & SATUAN & $\begin{array}{c}\text { HASIL } \\
\text { ANALISA }\end{array}$ \\
\hline 1 & $\mathrm{pH}$ & - & 4.13 \\
\hline 2 & N Total & $\%$ & 0.05 \\
\hline 3 & C Organik & $\%$ & 0.43 \\
\hline 4 & $\mathrm{P}_{2} \mathrm{O}_{5}{ }^{\circ}$ & $\mathrm{mgP}_{2} \mathrm{O}_{5} 100 \mathrm{~g} \mathrm{~g}^{-1}$ & 9.27 \\
\hline 5 & $\mathrm{~K}_{2} \mathrm{O}$ & $\mathrm{Cmol}^{-1} \mathrm{~kg}^{-1}$ & 1.49 \\
\hline 6 & $\mathrm{CaO}$ & $\mathrm{Cmol}^{-1} \mathrm{~kg}^{-1}$ & 0.75 \\
\hline 7 & $\mathrm{MgO}$ & $\mathrm{Cmol}^{-1} \mathrm{~kg}^{-1}$ & 2.19 \\
\hline 8 & KTK & $\mathrm{Cmol}^{-1} \mathrm{~kg}^{-1}$ & 8.58 \\
\hline 9 & $\mathrm{C} / \mathrm{N}$ & - & 9.52 \\
\hline
\end{tabular}

Tabel 4. Analisa Tanah N3 (15\% Mol Nasi Basi)

\begin{tabular}{|c|c|c|c|}
\hline NO & PARAMETER & SATUAN & $\begin{array}{c}\text { HASIL } \\
\text { ANALISA }\end{array}$ \\
\hline 1 & $\mathrm{pH}$ & - & 5.28 \\
\hline 2 & N Total & $\%$ & 0.04 \\
\hline 3 & C Organik & $\%$ & 0.49 \\
\hline 4 & $\mathrm{P}_{2} \mathrm{O}_{5}$ & $\mathrm{mgP}_{2} \mathrm{O}_{5} 100 \mathrm{~g} \mathrm{~g}^{-1}$ & 29.70 \\
\hline 5 & $\mathrm{~K}_{2} \mathrm{O}$ & $\mathrm{Cmol}^{-1} \mathrm{~kg}^{-1}$ & 0.62 \\
\hline 6 & $\mathrm{CaO}$ & $\mathrm{Cmol}^{-1} \mathrm{~kg}^{-1}$ & 1.39 \\
\hline 7 & $\mathrm{MgO}$ & $\mathrm{Cmol}^{-1} \mathrm{~kg}^{-1}$ & 3.00 \\
\hline 8 & KTK & $\mathrm{Cmol}^{-1} \mathrm{~kg}^{-1}$ & 9.43 \\
\hline 9 & $\mathrm{C} / \mathrm{N}$ & - & 10.07 \\
\hline
\end{tabular}

Berdasarkan data analisa laboratorium diatas dapat diihat bahwa penggunaan Mol nasi basi dengan taraf 5\%, 10\% dan 15\% tidak memberikan perubahan status hara tanah yang signifikan, hal ini dapat dilihat dari kandungan unsur hara makro yang terdapat pada tanah yakni N-total; sangat rendah, $\mathrm{P}_{2} \mathrm{O}_{5}$; rendah, dan $\mathrm{K}_{2} \mathrm{O}$; sangat rendah. Selain itu dapat dilihat bahwa kandungan $\mathrm{C} / \mathrm{N}$; rendah dengan Kapasitas Tukar Kation (KTK) pada keempat sampel tanah juga masuk ke dalam kategori yang rendah, hal ini menunjukan bahwa kemampuan 
tanah dalam menjerap dan/atau menyediakan unsur hara pada tanah relative rendah.

Berdasarkan hasil aplikasi hasil aplikasi Mol Nasi Basi pada papaya kalifornia menunjukan bahwa pemberian MOL nasi basi tidak berpengaruh nyata terhadap pertumbuhan tinggi tanaman, jumlah daun, dan diameter batang. Salah satu penyebabnya karena kandungan unsur hara dalam MOL nasi basi relatif kecil sehingga belum mampu menunjang dan memaksimalkan pertumbuhan tanaman.

Dari data lapangan diketahui bahwa pada parameter tinggi tanaman umur $15,30,45,60,75$ dan 90 HST rata-rata tinggi tanaman tertinggi terdapat pada perlakuan N0 yaitu $35,94 \mathrm{~cm}$ dan yang terendah terdapat pada perlakuan N3 yaitu $33,30 \mathrm{~cm}$. Pada parameter jumlah daun umur 15, 30, 45, 60, 75 dan 90 HST rataan jumlah daun tertinggi terdapat pada perlakuan NO yaitu 17,50 helai dan yang terendah pada perlakuan N1 yaitu 16,87 helai. Pada parameter diameter batang umur $15,30,45,60,75$ dan 90 HST rataan diameter batang tertinggi terdapat pada perlakuan N0 yaitu $19,92 \mathrm{~mm}$ dan yang terendah pada perlakuan N3 yaitu $18,16 \mathrm{~mm}$.

\section{KESIMPULAN}

Berdasarkan hasil penelitian yang telah dilakukan dapat disimpulkan bahwa respon pemberian Mol Nasi Basi terhadap pertumbuhan tidak memberikan hasil yang berbeda nyata pada tinggi, diameter dan jumlah cabang tanaman pepaya kalifornia.

\section{UCAPAN TERIMA KASIH}

Penulis mengucapkan terima kasih kepada Yayasan Pembina Pendidikan Mahakam dan Universitas Widya Gama Mahakam Samarinda atas bantuan biaya yang diberikan melalui Lembaga Penelitian dan Pengabdian Kepada Masyarakat pada skim hibah penelitian TA. 2020/2021 semester ganjil.

\section{DAFTAR PUSTAKA}

Afcarina, I. 2018. Pengaruh Dosis Dan Konsentrasi Mikroorganisme Lokal (Mol) Bonggol Pisang Terhadap Tanaman Sawi Hijau (Brassica rapa Var. Parachinensis L.) (Doctoral Dissertation, University Of Muhammadiyah Malang).

Arsela, P. 2018. Pengaruh Berbagai Varietas Dan Berbagai Pupuk Organik Cair Terhadap Pertumbuhan. Jurnal Agrifor Volume XVII Nomor 1.

Badan Pusat Statistik Kota Samarinda. 2019. Produksi Buah-buahan Menurut Jenis
Tanaman di Kota Samarinda (kuintal), 20142018. Retrieved from samarindakota.bps. go.id:https://samarindakota.bps.go.id/ statictable/2019 /09/13/271/produksi-buahbuahan-menurut-jenis-tanaman-di-kotasamarinda-kuintal-2014-2018.html.

Herniwati, \& Nappu, B. 2018. Peran dan pemanfaatan mikroorganisme lokal (MOL) mendukung pertanian organik. Retrieved from Balai Pengkajian Teknologi Pertanian Sulawesi Selatan : http://sulsel.litbang. Pertanian.go.id/ind/index.php/publikasi/buletin/5 2-buletin-nomor-5-tahun-2011/238-perandan-pemanfaatan-mikroorganisme-lokal-molmendukung-pertanian-organik.

Julita, S., Gultom, H., \& Mardaleni, M. 2013. Pengaruh Pemberian Mikro Organisme Lokal (Mol) Nasi Dan Hormon Tanaman Unggul Terhadap Pertumbuhan Dan Produksi Tanaman Cabai (Capsicum Annum L.). Dinamika Pertanian, 28(3), 167-174.

Sultoni, S., Miswan, M., \& Nur, A. R. A. C. 2019. Efektifitas Mikroorganisme Lokal (Mol) Limbah Nasi Sebagai Aktifator Pembuatan Pupuk Kompos Organik. Jurnal Kolaboratif Sains, 2.1.

Sumarno, S., Mahdalena, M., \& Hamidah, H. 2016. Pengaruh Berbagai Media Tanam Dan Pemberian Mikro Organisme Lokal (MOL) Keong Mas Terhadap Pertumbuhan Dan Produksi Tanaman Bawang Tiwai (Eleutherine americana). Agrifarm: Jurnal Ilmu Pertanian, 5(2), 37-40.

Suprihatin. 2010. Teknologi Fermentasi. Surabaya: UNESA University Press.

Selviana, Tri E. 2019. Pengolahan Limbah Nasi Basi Menjadi Pupuk Organik Cair Mikroorganisme Lokal (MOL) Bagi Tanaman. OSF Preprints. December 27. doi:10.31219/osf.io/snbdv. 